\title{
A tragédia neoliberal, a pandemia e o lugar do trabalho'
}

\author{
Graça Druck²
}

\section{Resumo}

Analisa o quadro do trabalho sob a hegemonia do neoliberalismo, antes da pandemia do coronavírus, apresentando alguns indicadores sobre a precarização do trabalho no setor privado e público. Defende a tese de que a pandemia desnudou a tragédia neoliberal, amplificando todas as mazelas do trabalho e questionando o lugar do Estado, ao mostrar a necessidade de políticas públicas e de investimentos para enfrentar essa crise humanitária, que obrigaram os governos atuarem na contramão do intervencionismo neoliberal. Analisa a realidade brasileira, antes e durante a pandemia, destacando os agravantes de viver uma pandemia sob um governo neofascista, cuja atuação foi genocida, enquanto as classes dominantes e seus representantes no executivo e no congresso nacional reafirmaram as políticas neoliberais, penalizando gravemente os trabalhadores. Aponta as perspectivas frente a uma recessão mundial, de crise de hegemonia do neoliberalismo, cuja crise econômica e social exigirá mais Estado social.

\section{Palavras-chave \\ Trabalho, neoliberalismo, pandemia}

The neoliberal tragedy, the pandemic and the place of work

\begin{abstract}
The article discusses the framework of work under the hegemony of neoliberalism, before the coronavirus pandemic, presenting some indicators about the precariousness of work in the private and public sector, defending the thesis that the pandemic exposed the neoliberal tragedy, amplifying all the ills in the world of work and questioning the place of the State, by showing the need for public policies and investments to face this humanitarian crisis, which made governments act against neoliberal interventionism. It analyzes the Brazilian reality, before and during the pandemic, highlighting the aggravating factors of living a pandemic under a neo-fascist government, whose performance was genocidal, at the same time that the ruling classes and their representatives in the executive and in the national congress reaffirmed the neoliberal policies, penalizing workers seriously. It also points out that post-pandemic perspectives, in the face of a global recession, will deepen the crisis of neoliberalism's hegemony, as the economic and social crisis will demand more welfare state.
\end{abstract}




\section{Keywords}

Work, neoliberalism, pandemic

Artigo recebido em junho 2020

Artigo aprovado em agosto de 2020

\section{A tragédia neoliberal antes da pandemia}

A crise mundial que está em curso desde a pandemia da Covid-19 colocou a nu para o mundo a tragédia neoliberal que nos últimos 40 anos devastou as sociedades capitalistas. Já se vivia numa situação de regressão social no nível global: altos níveis de desemprego, intensificação da precarização do trabalho, aumento da desigualdade, concentração de renda, empobrecimento, retirada de direitos, aumento dos sem teto, adoecimento ocupacional, desmantelamento da saúde pública, da previdência social e da educação pública, dentre outros. Resultado de um conjunto de contrarreformas e de políticas de governos neoliberais (trabalhista, previdenciária, estado, funcionalismo público, etc.).

Assim, já havia uma conjuntura de crise social em todo o mundo. Nos países da América Latina, em 2019, várias explosões e convulsões populares, movimentos e processos eleitorais se ergueram contra essa situação (Chile, Equador, Colômbia, México, Argentina). No caso brasileiro, as manifestações massivas em defesa da educação pública contra os ataques do governo Bolsonaro também pautaram esse momento.

A crise do coronavírus sintetiza todos os limites do capitalismo globalizado e a perversidade neoliberal: uma política de destruição, inclusive da vida. Considera-se o neoliberalismo em suas múltiplas interfaces: econômica, através do processo de globalização e financeirização da economia, constituindo um novo padrão de desenvolvimento - a acumulação flexível, que tem na precarização do trabalho uma dimensão central; politica, com o enfraquecimento das instituições democráticas e dos Estados Nacionais, estabelecendo novas estruturas 
de poder entre as classes; social, com o aumento das desigualdades, através de um processo inédito de concentração de riqueza e propriedade e de suspensão das políticas de redistribuição de renda; e ideológico, como uma nova "racionalidade" (DARDOT; LAVAL, 2016), hegemonizada pelos valores do empreendedorismo, da concorrência e da "mercantilização da vida", que passam a pautar a conduta de todas as classes - dominantes e dominadas.

As ações dos governos frente à pandemia se opuseram a tudo que em grande parte dos países vinha se processando sob o intervencionismo neoliberal, que mercantilizou a vida, a saúde, a educação, negando as políticas públicas e o direito do trabalho, descontruindo os estados sociais, estabelecendo um estado gerencial e empresarial, cujas contrarreformas se sustentaram na ideologia do empreendedorismo, do homem empresa, da privatização dos serviços públicos e da gestão estatal. A crise sanitária, o colapso da saúde pública e a inexistência de sistemas de saúde pública foram decisivos para aumentar a tragédia, com o alto índice de contaminação e de mortes. Tendo no isolamento social a única "arma" contra o vírus, os governos tiveram que deliberar sobre políticas públicas emergenciais, a fim de evitar uma calamidade maior.

Nessa crise social, econômica, política, ambiental e humanitária, se evidenciou que o Estado é o único instrumento que pode minorar os efeitos dessa tragédia, como vem se demonstrando no mundo inteiro, mesmo em países cujos governos eram alinhados às políticas neoliberais.

No caso brasileiro, há alguns agravantes que antecedem a pandemia e que já caracterizavam um quadro alarmante, pois já se vivia uma profunda precarização social decorrente das políticas de um neoliberalismo radicalizado e fundamentalista aplicadas no país desde 2016, a exemplo da Emenda Constitucional 95, que congelou os gastos sociais por 20 anos, a contrarreforma trabalhista que estabeleceu a precarização como regra, a contrarreforma da previdência, cujas regras adiaram a aposentadoria para milhões de brasileiros; os cortes nos or- 
çamentos para a educação e a saúde pública, colocando em xeque o SUS e a pesquisa no país, e um conjunto de medidas provisórias, portarias e projetos de emendas constitucionais que tinham como foco, a redução do número de funcionários públicos, o fım da estabilidade, a substituições dos contratos em regime jurídico único por CLT, terceirizações e contratos temporários; a diminuição dos recursos destinados à pesquisa, quando $90 \%$ dela é realizada pelas universidades públicas; e a censura, controle e descaso com instituições de fomento à pesquisa e produção de informações (CNPq, Capes, IBCE, dentre outros).

Assim, o quadro do trabalho no setor público e privado no Brasil antes da pandemia já revelava a tragédia neoliberal. Segundo dados da PNAD contínua, de janeiro a março de 2020, eram 12,9 milhões de desocupados e 36,5 milhões na informalidade, totalizando 49,4 miIhões sem qualquer proteção social e trabalhista. Eram 27,6 milhões de força de trabalho subutilizada, que agrupa desempregados, subocupados por insuficiência de horas (estão empregadas, mas gostariam e poderiam trabalhar mais) e a força de trabalho potencial ${ }^{3}$.

Dentre os autônomos e sem carteira, estão os entregadores de aplicativos, como um dos segmentos que mais cresce no país, resultado de uma nova reestruturação produtiva, cujo centro está no novo padrão tecnológico, que permite às empresas-aplicativo utilizar o trabaIho e os meios de trabalho do trabalhador, sem qualquer vínculo de emprego, ainda que com processos de trabalho taylorizados, sob total controle dessas empresas, mas que negam qualquer relação trabaIhista (ABILIO et al, 2020, FILGUEIRAS e ANTUNES, 2020) e que caracteriza a era da "servidão digital" (ANTUNES, 2019).

Um quadro, portanto, em que se combinam as políticas ultraneoliberais, de desregulamentação do mercado de trabalho, vide a contrarreforma trabalhista de 2017 e a "carteira verde e amarela", com o uso das novas tecnologias de informação, onde a "uberização" passa a contaminar várias profissões, como é o caso de advogados, médicos, enfermeiros, professores, dentre outras. 
No âmbito do trabalho no serviço público, os efeitos da EC 95, de congelamento dos gastos sociais, levaram a cortes nos orçamentos para educação, saúde, pesquisa, dentre outros, e de um verdadeiro assédio moral institucional e midiático aos funcionários públicos, desqualificando-os para justificar uma "reforma administrativa”, cujo principal objetivo é o de radicalizar a contrarreforma do aparelho do estado dos anos 1990, suspendendo concursos, aumentando os contratos temporários e a terceirização, esta agora sem qualquer limite e com amparo legal, reduzindo o quadro efetivo dos estatutários, e quebrando a estabilidade.

Antes da pandemia já estava em curso uma verdadeira campanha para desqualificar e desmoralizar os funcionários públicos, divulgando e distorcendo informações, destituindo-os da sua natureza fundamental, que é a de serem os agentes que executam e garantem o atendimento público em todas as áreas sociais. Sem eles, ou com um contingente cada vez mais reduzido, fica impraticável manter serviços para uma população de 210 milhões de pessoas, o que foi evidenciado pela pandemia.

O mito de que o Estado brasileiro arrecada muito e é grande e inchado, pode ser desmentido pelos dados. Informações divulgadas pela OCDE, utilizadas pelo Banco Mundial em documento encomendado pelo governo brasileiro para justificar as reformas do Estado "Gestão de pessoas e folha de pagamentos no setor público brasileiro: o que dizem os dados?" -, mostram em 2015, que a carga tributária no Brasil foi de $35,6 \%$ do PIB, enquanto que na OCDE foi de 42,4\%. A proporção de empregados no setor público em relação ao total da população ocupada no Brasil era de 12\% e na OCDE, 21,3\%. Dado que levou o próprio Banco Mundial a reconhecer que o Brasil tem um "número modesto de funcionários públicos".

Em 2017, o Brasil tinha um total de 11,7 milhões de funcionários públicos, o que correspondia a $11 \%$ da população economicamente ativa. Desses, 6,5 milhões ou 57\% estavam nos municípios; é também aí que a remuneração é a menor e onde trabalha a imensa maioria 
dos funcionários da saúde, da educação e da segurança, que correspondem a $60 \%$ dos funcionários nos municípios. Os funcionários públicos estaduais eram 3,7 milhões ou $32.7 \%$ e no nível federal somavam 1,18 milhão de funcionários civis e militares, ou 10\% do total ${ }^{4}$. As despesas do governo com salários estavam distribuídas da seguinte forma: $15 \%$ com o judiciário, 3\% com o legislativo, 2,5\% com o ministério público e $79 \%$ com o executivo, onde está inserida a maioria dos funcionários que desempenham as atividades essenciais no atendimento aos direitos sociais da sociedade.

Ainda conforme o Atlas do Estado Brasileiro, o crescimento do número de funcionários é diferente para cada nível federativo. Entre 1995 e 2016, os federais aumentaram $25 \%$, os estaduais cresceram $28 \%$ e os municipais $175 \%$, decorrente da municipalização dos serviços públicos, especialmente, saúde, educação e assistência social e, também, do aumento do número de municípios.

A despesa com pessoal em termos de proporção do PIB se manteve estável, era de 9,6\% em 2006 e passou a 10,5\% em 2017. Ou seja, não houve nenhum descontrole de gastos, tão alardeado pelo atual governo.

Ao se examinar a composição do orçamento federal executado em 2019, o governo gastou 38,3\% (R\$1,038 trilhão de reais) com o pagamento de juros e amortizações da dívida pública, destinados às instituições financeiras e bancos. Dívida essa que nunca foi auditada nos termos constitucionais. Já as áreas sociais, como educação, saúde, segurança pública, assistência social e transferências para estados e municípios somaram 21,9\% do total gasto pelo governo, conforme dados da Auditoria Cidadã da Dívida.

Em 2019, as universidades federais sofreram o maior corte e contingenciamento de recursos em sua história. O Ministério da Educação, condenando as universidades federais como centros de "balbúrdia", decidiu penaliza-las, contingenciando e bloqueando recursos, levando a um processo de estrangulamento dessas instituições. Os primeiros resultados dramáticos atingiram os mais vulneráveis e pre- 
carizados da Universidade: os trabalhadores terceirizados. O pagamento dos serviços terceirizados representa aproximadamente 60\% das verbas de custeio da universidade. Diante da indisponibilidade dos recursos, as empresas prestadoras de serviços começaram a demitir, justificando as demissões pela falta de repasse dos recursos e responsabilizando as Universidades. Tal situação é de uma gravidade extrema, pois as universidades públicas -, que só podem funcionar com o trabalho desses terceirizados (limpeza, vigilância, portaria, etc.), ou seja, serviços essenciais - se tornaram reféns das empresas privadas que intermediam os contratos e que tem uma longa história de descumprimento dos direitos trabalhistas.

O pacote de reformas denominado "Mais Brasil" pelo governo, constituído por três Propostas de Emendas Constitucionais (PEC 186,187 e 188) tem como fio condutor a redução das despesas públicas exclusivamente com as políticas sociais, subordinando o volume de recursos a serem aplicados na área social ao "equilíbrio fiscal intergeracional", isto é, que garanta a "sustentabilidade" da dívida pública. Assim os direitos sociais não serão mais garantidos pela constituição, pois estarão submetidos aos gastos financeiros do Estado.

As empresas estatais, especialmente o caso do Banco do Brasil e da Petrobras, dois grandes patrimônios da sociedade brasileira, vêm sofrendo processos de reestruturação interna e com venda de ativos, caso da Petrobras, desde 2016. A “razão neoliberal” dirige a reestruturação organizacional dessas empresas, com incentivos a aposentadorias, planos de demissão voluntária, transferências compulsórias, redução de benefícios, com uma diminuição enorme do contingente de trabalhadores concursados ao lado do uso da terceirização e de contratos precários. Em 2019, já sob a direção do governo Bolsonaro, acelerou-se o processo de privatização da $\mathrm{Pe}-$ trobras, redução do quadro, e uma postura antissindical da direção da empresa, desrespeitando convenções coletivas e sem qualquer diálogo com os sindicatos. 


\section{O quadro do trabalho durante a pandemia}

Todos os indicadores já referidos antes da pandemia que caracterizavam um quadro altamente precário do mercado de trabalho brasileiro foram fortemente amplificados. De acordo com a Pnad contínua (IBCE, 2020), no trimestre fevereiro/abril de 2020, houve uma redução de 4,9 milhões de ocupações em relação ao trimestre anterior. $O$ número de desocupados atingiu 13.177 milhões de pessoas. A força de trabalho subutilizada, que reúne desocupados, subocupados por insuficiência de horas, força de trabalho potencial, chegou a 28,7 milhões de trabalhadores, ou seja, em um mês, esse contingente aumentou em $21 \%$. O total na informalidade era de 39,9 milhões de trabalhadores. Portanto, eram 68,6 milhões sem proteção social e trabalhista. O número de solicitações de seguro desemprego em maio de 2020 chegou a quase 1 milhão, $28,3 \%$ a mais do que em abril (748.540) ${ }^{6}$.

Segundo dados da primeira PNAD Covid-19, somente no mês de maio, cerca de 17,7 milhões de pessoas não conseguiram procurar emprego devido à pandemia. Somente naquele mês, eram 28,6 milhões que queriam um emprego, mas não conseguiram, por falta de vagas ou porque ficaram impedidos de procurar trabalho por conta do coronavírus.

Considerando que a pandemia não havia ainda atingido o seu pico em junho de 2020, esses números referentes a dois meses - março e abril - já indicam a tendência de agravamento da situação do mercado de trabalho brasileiro.

É neste grave quadro, que vale destacar a condição dos trabalhadores entregadores de aplicativos. Eles são parte do conjunto da força de trabalho que está sem proteção social e trabalhista, apesar de se tornarem, durante a pandemia, serviços essenciais. Em pesquisa realizada em maio de 2020 por pesquisadores da REMIR - Rede de Estudos e Monitoramento da Reforma Trabalhista ${ }^{7}$, 60,3\% dos entrevistados declararam que houve queda na remuneração e aumento da jornada de trabalho, $57 \%$ trabalham mais de 9 horas diárias, 19,3\% entre 11 e 12 horas por dia, 9,4\% dos entrevistados tornaram-se entregadores durante a pandemia. 
Nesse período, mesmo com um aumento significativo da demanda por entrega a domicílio, as empresas diminuíram o valor da hora de trabalho e/ou bonificação, o que pode explicar a queda da remuneração aliada ao aumento do número de entregadores. Assim, se antes já arriscavam suas vidas para cumprir as metas e/ou para obter alguma remuneração para sobreviverem, agora se acrescenta a exposição cotidiana à contaminação pelo coronavírus, numa situação de poucas medidas preventivas adotadas pelas empresas e nenhum compromisso dessas com o adoecimento ou mesmo morte desses trabalhadores. Condições que levaram a um movimento nacional dos entregadores de aplicativos organizando uma greve marcada para 1 de julho ${ }^{8}$.

Ao lado desses indicadores, há outro agravante da realidade brasileira: o quadro político do país. A existência de um governo neofascista que insiste em opor a saúde e a vida das pessoas à economia, acirrando a crise sanitária e da saúde, estimulando as disputas politicas internas e aprofundando a crise política em meio aos efeitos desastrosos da pandemia. Um governo que nega a ciência e o conhecimento produzido por instituições credenciadas como a OMS, com aparições e declarações do presidente da república desqualificando as medidas tomadas e recomendadas, a exemplo do isolamento social, desprezando as vitimas da pandemia, demonstrando não ter qualquer empatia social. Um governo que ameaça permanentemente as instituições democráticas e defende a radicalização das políticas neoliberais, cujo espírito está presente nas medidas adotadas frente à crise da pandemia, pois as ações emergenciais para socorrer os mais pobres e desprotegidos foram insuficientes. Ao mesmo tempo, no Congresso Nacional, as pautas e votações de medidas provisórias e projetos de leis penalizavam gravemente os trabalhadores.

Nessa profunda crise sanitária, econômica, social e política, se evidencia a enorme desigualdade de recursos disponibilizados pelo governo para combater a pandemia. De acordo com dados oficiais do Tesouro Nacional, o "Auxílio emergencial a pessoas em situação 
de vulnerabilidade" destinados aos trabalhadores informais, que reúnem os trabalhadores sem carteira, trabalhadores domésticos sem carteira, empregadores sem CNPJ, os conta própria sem CNPJ e trabalhadores familiares auxiliares, definido em 600,00 reais pelo Congresso Nacional, disponibilizou 98,2 bilhões de reais O Programa Emergencial de Manutenção do Emprego e da Renda (MP 936) com redução de jornada e de salário, além de suspensão de contratos, sem vetar demissões, cujo beneficio pago pelo governo tem como referência o valor do seguro desemprego, disponibilizou um total de 51,6 bilhões. A concessão de financiamento para pagamento de folha salarial para pequenas e médias empresas era de 34 bilhões de reais. Somando outros gastos como ampliação do Bolsa Família, recursos diretos para a saúde, e outros, chega-se ao total de uma disponibilização de recursos de 224,16 bilhões de reais. Desses, após 3 meses de pandemia, tinham sido executados 79\%, sendo que o Programa Emergencial de Manutenção do Emprego e da Renda, apenas 22,7\%; ampliação do bolsa família, 10,8\% e concessão de financiamento para pagamento de folha salarial para pequenas e médias empresas, 50\% ${ }^{9}$.

O Congresso aprovou o "Programa Federativo de Enfrentamento ao Coronavírus (Lei 723)”, encaminhado pelo governo, conhecido como ajuda aos estados e municípios para o combate à Covid-19. Entretanto, como condição para aprovar esse auxílio, o governo Bolsonaro, através do Ministro Paulo Guedes, introduziu no corpo do projeto de lei, o congelamento de salários, de progressões na carreira e de suspensão de concursos até 31 de dezembro de 2021. Emendas parlamentares, fruto da pressão de sindicatos e movimentos sociais, excluíram desse congelamento os servidores das áreas da saúde, educação, segurança pública e das Forças Armadas. O presidente esperou 25 dias para sancionar o PL e vetou essas emendas, mantendo o congelamento salarial, inclusive para os trabalhadores da área de saúde, que estavam na linha de frente do combate ao coronavírus. 
O argumento do Ministro da Economia10 era que os funcionários públicos tinham que se sacrificar e dar a sua contribuição para enfrentar a pandemia. É importante lembrar que o sacrifício de grande parte dos funcionários públicos já estava em execução desde o início da contaminação pela Covid-19 no país. As condições precárias de trabalho, de salário e de proteção e segurança desses profissionais já era objeto de denúncia dos sindicatos e instituições que reúnem estudiosos sobre a saúde dos trabaIhadores e sobre o SUS há muitos anos. Situação que se agravou violentamente com a pandemia: falta de equipamentos de proteção, de material, de medicação, de leitos, de infraestrutura, de pessoal, e os baixos salários, além de jornadas extensas é a regra entre os trabalhadores da saúde.

Assim, o total de recursos disponibilizados para enfrentar a pandemia até junho de 2020 era de 349,16 bilhões de reais, destinados aos mais vulneráveis e a empresas de pequeno e médio porte. Enquanto isso, o governo, através de um conjunto de medidas do Banco Central em abril de 2020, decidiu injetar recursos no sistema financeiro, cujo montante disponibilizado para os bancos chegou a 1,216 trilhão de reais, o que corresponde a $16,7 \% \mathrm{PIB}^{11}$. Uma politica que escancara o desigual tratamento das classes sociais, beneficiando de forma escandalosamente desigual os banqueiros em detrimento da maioria da sociedade.

Dessa forma, para além da natureza mais geral do Estado capitalista como um estado de classe, as ações e políticas do executivo, apoiadas pela maioria do legislativo, evidenciam não só essa natureza, como reafirmam os "trilhos neoliberais" defendido pela agenda de reformas pautada num permanente "ajuste fiscal", que transfere recursos públicos para os rentistas e defende corte de salários dos funcionários públicos e o congelamento de salários, carreira e concursos.

\section{O trabalho no setor privado e público sob o fogo da pandemia e do fundamentalismo neoliberal}

A tendência já revelada nessa crise humanitária -, de uma pandemia que evidenciou fortemente o fracasso do capitalismo flexível 
financeirizado, do fundamentalismo neoliberal e de um Estado gerencial/empresarial que negou a necessidade de políticas públicas -, é de uma recessão econômica mundial, e avalia-se que pode ser maior do que a crise de 29.

A recessão - cujo principal indicador é o nível crescente de desemprego, por conta de uma retração na atividade econômica, queda do PIB, queda na renda familiar, falências, etc. - no caso brasileiro, já se manifestava após três meses de pandemia e é reconhecida por economistas das mais diferentes perspectivas teóricas e ideológicas ${ }^{12}$, que afırmam a gravidade da crise e a necessidade de uma intervenção do Estado com a aplicação de políticas públicas, com investimentos em infraestrutura, inclusive em saneamento básico e saúde, e implementação de programas de renda básica universal.

De acordo com estudo de pesquisadores do Cecon/IE/Unicamp ${ }^{13}$, já no primeiro trimestre de 2020, ocorreu uma contração de $-1,5 \%$ no PIB, com recuo nas exportações (-0,9\%), consumo das famílias (-2\%), do setor de serviços $(-1,6 \%)$, além da queda nas ocupações. A desaceleração já vinha ocorrendo antes de iniciar a pandemia, e com o início da contaminação no Brasil, se transformou em contração. A conjuntura de crise econômica anterior à pandemia pode explicar o que a OCDE e ECDC analisam a "divergência entre contágio econômico e transmissão viral”, isto é, a desaceleração econômica é relativamente mais rápida do que a difusão da pandemia e anterior às primeiras medidas de isolamento social. Por tudo isso, os pesquisadores do Cecon afirmam que a queda do PIB e o aumento do desemprego no primeiro trimestre de 2020 não é culpa da política de saúde pública, mas destacam a reversão de expectativas do capital, diante da conjuntura internacional e do movimento do mercado financeiro, pois nesse primeiro semestre, ocorreu a maior saída de capitais estrangeiros dos mercados emergentes, superior aos piores momentos da crise de 2008-2009. Em relatório "Perspectiva Econômica Global - uma crise como nenhuma outra, uma recuperação incerta”, de 
junho de 2020, o FMI projetava uma contração do PIB brasileiro de 9,1\% neste ano e de 4,9\% no nível mundial, e recomendava o investimento público, especialmente na área de saúde ${ }^{14}$.

Tais informações são importantes para rebater a defesa principista e fundamentalista dos setores empresariais que estão representados por Paulo Guedes no Ministério da Economia, que tem como única resposta à crise, mais do mesmo, isto é, aprofundar as contrarreformas - do trabalho, previdenciária e do Estado - na defesa de um permanente ajuste fiscal, responsabilizando os gastos sociais do governo com as políticas públicas de educação, saúde, segurança, assistência social, etc. e os agentes executores dessas políticas - os funcionários públicos. Uma postura que tem se efetivado num conjunto de Propostas de Emendas Constitucionais (PECs), Projetos de Lei (PLs) e Medidas Provisórias (MPs) antes e durante a pandemia, que penalizam os trabalhadores em geral (MP936) e os funcionários públicos em particular (Lei 723 e MP922).

As medidas emergenciais definidas pelo governo e pelo congresso nacional, comparativamente a outros países da América Latina, foram tímidas e insuficientes, e ainda com demora na liberação de recursos e atraso na sua execução. Uma política de chantagem com os estados e municípios, retardando o repasse de recursos e a suspensão das dívidas, indicador de um comportamento genocida do governo federal ${ }^{15}$. Ao lado da constante reafirmação do Ministério da Economia sobre a necessidade de pautar e aprovar no Congresso a continuidade das contrarreformas; especialmente a "Reforma Administrativa", que tem por objetivo redefinir o estatuto do funcionalismo público, numa perspectiva de reduzir o seu número e adotar todo tipo de contrato flexível e precário, seja através da terceirização, de organizações sociais, contratos temporários e outras modalidades afins, colocando fim aos concursos públicos e ao regime jurídico único.

Vale destacar dentre as medidas do governo aprovadas no congresso, a Lei 723, que congelou salários, concursos públicos e carreiras 
dos funcionários públicos, complementada pela MP 922, que define os contratos temporários, que poderão durar de 6 meses a 4 anos, e em alguns casos até 8 anos; dispensa processo seletivo e editais de ampla divulgação, com contratação por "notória capacidade técnica", mediante análise de currículo e a contratação de servidores aposentados pagos por adicional de produtividade no limite de até 35\% do salário da ativa. É o início da chamada "reforma administrativa" do Estado, justificada pelo governo pela urgência sanitária, indicador de uma contrarreforma trabalhista no funcionalismo público.

Além dos índices de desemprego, de subutilização da força de trabalho, da informalidade atingirem níveis altíssimos em três meses de pandemia, com fechamento de postos de trabalho e de redução das atividades informais, com queda de rendimentos, vale registrar o processo de precarização para aqueles que continuaram trabalhando, caso mais perverso para os que estavam inseridos nas atividades essenciais. Ao mesmo tempo em que se sentiam aliviados por manter seus empregos ou sua atividade, sabiam que para isso arriscavam a vida diariamente, pelos riscos de contaminação. Eram os que estavam nas áreas de alimentação, transportes, saúde, serviços domésticos, segurança e outros serviços. A compulsoriedade do trabalho domiciliar, através do home office, por exemplo, reconfigurou completamente o ambiente, as relações e as condições de trabalho, obrigando a jornadas mais extensas, sofrimento com o uso de novas tecnologias para as quais não havia treinamento, com um alto custo de insumos e recursos agora totalmente suportados pelos próprios trabalhadores, o isolamento social sem a convivência e apoio dos colegas de trabalho.

O caso dos trabalhadores da área de saúde, especialmente os que trabalhavam no SUS, adquiriu relevância, atenção, indignação e solidariedade. Na linha de frente da guerra ao coronavírus, foram se contaminando, adoecendo e morrendo. As estatísticas revelam um quadro desolador. 
A realidade do trabalho no Brasil - no setor público e privado - se antes da pandemia já mostrava o grau de precariedade e de perda de direitos, durante a crise sanitária, foi objeto de políticas que amplificaram a precarização social do trabalho e cuja tendência já referida de uma violenta recessão mundial, só poderá aprofundar essa crise, se o curso da história no país não for revertido, isto é, se não for possível interromper o intervencionismo neoliberal.

Historicamente, a experiência de crises econômicas e sanitárias, e de uma crise humanitária, mostraram que para tentar minorar os efeitos dessas tragédias, o Estado tem um papel crucial no desenvolvimento de políticas públicas de emprego e renda, saúde, educação e assistência social. Assim, quanto mais profunda a crise do mercado de trabalho, maior demanda por serviços públicos pela sociedade e, portanto, se tornam ainda mais necessários os funcionários públicos, os agentes encarregados de executar estas políticas.

\section{Algumas considerações finais}

A precarização social do trabalho é um processo econômico, social e político que se tornou hegemônico e central na atual dinâmica do capitalismo flexível - no contexto de mundialização do capital e das políticas de cunho neoliberal. Trata-se de uma estratégia patronal, em geral apoiada pelo Estado e seus governos, que tem sido implementada em todo o mundo, cujos resultados práticos se diferenciam muito mais por conta da história passada de cada país, refletindo os níveis de democracia, de organização e de conquistas dos trabalhadores, do que da história presente, cujos traços principais os aproximam e os tornam semelhantes, pois a precarização social do trabalho se impõe como regra e como estratégia de dominação assumindo um caráter cada vez mais internacionalizado. (DRUCK, 2013)

O processo atual de precarização, como um movimento em curso há aproximadamente 40 anos, é fruto de uma correlação de forças entre as classes sociais em que os trabalhadores foram derrotados, e 
o neoliberalismo se tornou hegemônico a nível mundial. As primeiras experiências neoliberais que datam dos anos 1970, a começar pelo Chile, após o golpe militar com Pinochet, e posteriormente na Inglaterra e Estados Unidos, foram se reproduzindo por todo o mundo.

Assim como a precariedade, que é estrutural no capitalismo, se metamorfoseia, transformando-se constantemente na história, o capitalismo neoliberal também sofre transformações. No seu desenvolvimento, se constituiu na vanguarda político-ideológica do capitalismo financeirizado e dos Estados imperialistas, produzindo implicações gravíssimas para as condições de vida e trabalho da maioria da população mundial, constituindo uma nova hegemonia ou uma "nova racionalidade" (DARDOT; LAVAL, 2016), apoiada na concorrência de todos contra todos, estimulada pela ideologia do "empreendedorismo" e pela "ditadura do sucesso", e constituindo um "novo modo de vida".

Entretanto, vive-se um novo momento do neoliberalismo, em que se radicalizam todos os seus traços, adquirindo um tom fundamentalista, quase religioso, sustentado cada vez menos em sua capacidade ideológica e de convencimento e cada vez mais na imposição de seus valores e das políticas de austeridade, como única via para a preservação da sociedade capitalista. Expressão disso é a maior crise da democracia liberal na história que, cada vez mais deixa de ser útil ao neoliberalismo, alimentando, desta forma, os movimentos neofascistas e os governos que os representam.

Um momento histórico em que esse "novo neoliberalismo", (DARDOT; LAVAL, 2019), ou o "fascismo neoliberal” (FILCUEIRAS; DRUCK, 2019) ou "momento fascista do neoliberalismo" (FASSIN, 2018) está indicando a existência de uma crise de hegemonia nessa sociedade neoliberal. Isso porque há um esgotamento das condições objetivas criadas pelo capitalismo neoliberal. Ao lado dos avanços tecnológicos até então inimagináveis e do extraordinário crescimento da riqueza material e financeira, propiciada pela nova forma de estruturação e funcionamento do capitalismo, houve um aumento escan- 
daloso da concentração da riqueza e da renda em quase todos os países, o crescimento da pobreza, o distanciamento cada vez maior entre os países centrais e os países periféricos, a elevação do desemprego estrutural, a precarização do trabalho, o ataque ao direito do trabalho e abolição dos direitos sociais e a desmoralização das instituições da democracia liberal.

Nesse novo cenário, os problemas sociais criados em todo o mundo, em decorrência da política neoliberal se agigantaram, e este sistema se mostra incapaz de trazer qualquer solução a esse quadro. Ao contrário, segundo Dardot e Laval (2019, p. 2), “o que caracteriza este modo de governo é que se alimenta e se radicaliza por meio de suas próprias crises. O neoliberalismo só se sustenta e se reforça porque governa mediante a crise", à medida que, ao contrário de questionar a lógica que a criou, busca mantê-la e radicaliza-la, reforçando-a permanentemente. Trata-se da crise "como forma de governo". (DARDOT; LAVAL, 2019, p.2) o que justifica as políticas de "ajuste fiscal" permanente.

É o que se assistiu, no caso brasileiro, durante a pandemia do coronavírus que, conforme já referido, desnudou a tragédia neoliberal amplificando-a, e o governo com o apoio de todos os setores empresariais, mesmo aqueles críticos à postura do governo em relação à crise sanitária, e da maioria do Congresso Nacional, aprofundaram as medidas de cunho neoliberal, reduzindo direitos sociais e trabalhistas, penalizando a classe trabalhadora, através da redução de salários e jornada, permitindo a demissão em massa, impondo a negociação individual, neutralizando os sindicatos, congelando salários, carreira e concursos públicos, ampliando as formas precárias e temporárias de contratação no serviço público, iniciando uma "reforma administrativa" do estado justificada pelo caráter emergencial da pandemia, além da defesa enfática e permanente do Ministro da Economia e de dirigentes do Congresso Nacional, de que a única forma de enfrentar as perdas econômicas eram as reformas, especialmente, a "reforma do estado". 
Em plena crise humanitária, o que se observa é a voracidade do capital sem qualquer renúncia em se apropriar do fundo público. Esse, historicamente, é objeto de disputa permanente e reflete as relações de forças entre as classes. Em tempos neoliberais do capitalismo financeirizado, o estado e o orçamento público têm sido capturados de forma avassaladora pelo capital, seja pela transferência de recursos públicos para os rentistas, através do pagamento de juros e amortizações da dívida pública, representando a maior fatia do orçamento, seja através da estrutura tributária regressiva, penalizando os mais pobres. A Emenda Constitucional 95 congelou gastos sociais em nome da "crise fiscal", mas não pôs nenhum limite ao pagamento da dívida pública. O "Plano mais Brasil”, conforme já referido, subordina os gastos com políticas sociais à sustentação dessa dívida, que jamais foi auditada, embora tenha inúmeras evidências de irregularidades e inconstitucionalidades.

O fundo público é indispensável para a reprodução do capital, nas mais diferentes modalidades: subsídios, desonerações tributárias, incentivos fiscais, financiamento das políticas públicas; política tributária e dívida pública (SALVADOR, 2012). No caso brasileiro, de um capitalismo financeirizado e flexível, sob a diretriz neoliberal num país da periferia, tais modalidades foram absolutamente todas definidas a favor exclusivamente do capital, refletindo a correlação de forças entre as classes sociais, onde a classe trabalhadora sofreu enormes perdas, amplificando de forma inédita a estrutural desigualdade econômica e social.

É através também do fundo público que o Estado pode responder a situações de crises humanitárias e de períodos de estagnação e de recessão econômica. É o que se observa em todo o mundo, a partir da crise da pandemia. Mesmo que os governos tenham determinado doses diferentes de aplicação de recursos para "salvar" a economia, foram forçados a usar parte desses recursos para dar alguma proteção aos trabalhadores, especialmente aos mais pobres e desassistidos, para evitar o caos social. 
As revelações trazidas por uma crise humanitária mundial, que agravou a tragédia neoliberal do capitalismo financeirizado e globalizado, tem como um dos elementos chave a centralidade do trabalho em suas mais diversas manifestações. Conforme já analisado, os indicadores de precarização social do trabalho, antes e durante a pandemia, determinam o tamanho da crise, assim como indicam as tendências e possibilidades futuras.

Em meio ao desastre sanitário, econômico, social e político vivenciado no país, várias iniciativas e novas formas de organização foram criadas pelos movimentos sociais, culturais e sindicais. A transversalidade das lutas ganhou terreno, começando a questionar as fronteiras ou os limites de cada movimento, enfraquecendo as disputas políticas entre os subalternos, diminuindo a divisão e a fragmentação das classes trabalhadoras. A luta pela vida, por um trabalho digno, por direitos sociais e trabalhistas, por moradia, pelo SUS, por direitos iguais para negros e mulheres, por educação pública de qualidade, pela defesa da natureza, por liberdade de expressão e organização e por democracia foram traduzidas num amplo movimento que manifestou a vontade coletiva de retirar o país das mãos de governantes que representam a negação de tudo isso e a destruição de milhões de vidas dos brasileiros.

\section{Referências}

ABÍLIO, Ludmila Costhek, ALMEIDA, Paula Freitas, AMORIM, Henrique, CARDOSO, Ana Claudia Moreira, FONSECA, Vanessa Patriota da, KALIL, Renan Bernardi, MACHADO, Sidnei. Condições de trabalho de entregadores via plataforma digital durante a Covid-19. Revista Jurídica Trabalho e Desenvolvimento Humano. Procuradoria Regional do Trabalho da 15a Região, junho 2020.

ANTUNES, Ricardo. O privilégio da servidão - o novo proletariado de serviços na era digital, SP, Boitempo, 2019.

AUDITORIA CIDADÃ DA DÍVIDA. Orçamento Federal Executado (Pago) em $2019=R \$ 2,711$ trilhões, 2020. In: https://auditoriacidada.org.br/conteudo/ grafico-do-orcamento-federal-2019-2/. Acesso em 15/03/2020. 
BANCO MUNDIAL. "Gestão de pessoas e folha de pagamentos no setor público brasileiro: o que dizem os dados?", 2019.

BASTOS, Pedro Paulo Zahluth; GOMES-Jr, Luiz Celso, DOURADO Lorena Salces, PETRINI, ROBILLOTI, Paulo, IBARRA, Antonio. O impacto econômico da pandemia do Covid-19 e a contração do PIB no primeiro trimestre de 2020: não é culpa da política de saúde pública. Disponível em: https://www.economia.unicamp.br/images/arquivos/nota_cecon_14_PIB_corona.pdf, Acesso em: 1 jun 2020.

BRASIL. Tesouro Transparente. Disponivel em: https://www.tesourotransparente.gov.br/visualizacao/painel-de-monitoramentos-dos-gastos-com-covid-19, em 23/06/2020.

BRASIL. Banco Central anuncia conjunto de medidas que liberam R\$1,2 triIhão para a economia. Disponível em: https://bityli.com/pkQUT. Acesso em 25 abr. 2020.

DARDOT, P.; LAVAL, C. A nova razão do mundo: ensaio sobre a sociedade neoliberal. São Paulo: Boitempo, 2016.

DARDOT, P. LAVAL, C. A “nova” fase do neoliberalismo, Disponível em: https://outraspalavras.net/outrasmidias/dardot-e-laval-a-nova-fase-do-neoliberalismo/, 29/07/2019. Acesso em: 12/12/2019.

DIEESE/FUP. Dados sobre evolução de investimentos e de funcionários na Petrobras. 2020, mímeo.

DRUCK, G. Precarização Social do Trabalho (verbete) IN: IVO, A. (org) Dicionário Temático Desenvolvimento e Questão Social, Ed Annablume, 2013, pp 373-381.

FASSIN, E. “Le moment néofasciste du néolibéralisme”, Mediapart, 29 de junho de 2018, Disponível em: https://blogs.mediapart.fr/eric-fassin/blog/290618/ le-moment-neofasciste-du-neoliberalisme, Acesso em: 15/10/2019 .

FILGUEIRAS, L., DRUCK, G. O neoliberalismo neofascista do governo Bolsonaro e os desafios para a esquerda. 2019. Disponivel em: https://marxismo21.org/wp-content/uploads/2019/12/Luiz.

FILGUEIRAS, V., ANTUNES, R.Plataformas digitais, uberização do trabalho e regulação no capitalismo contemporâneo, 2020, Contracampo, vol 39, $\mathrm{n}^{\circ} 1$, abr/jul 2020. Disponivel em: https://periodicos.uff.br/contracampo/article/ view/38901/html. Acesso em: 15/05/2020. 
FUNDO MONETÁRIO INTERNACIONAL. "Perspectiva Econômica Global uma crise como nenhuma outra, uma recuperação incerta". Disponivel em: https://www.imf.org/es/Publications/WEO/Issues/2020/06/24/WEOUpdateJune2020. Acesso em: 25/jun/2020.

IBGE. PNAD contínua, 2020. Disponivel em: https://agenciadenoticias.ibge. gov.br/agencia-sala-de-imprensa/2013-agencia-de-noticias/releases/ 27534-pnad-continua-taxa-de-desocupacao-e-de-12-2-e-taxa-de-subutilizacao-e-de-24-4-no-trimestre-encerrado-em-marco-de-2020. Acesso em: 15/04/2020.

IBCE. PNAD Covid19, 2020.

IPEA. Atlas do Estado brasileiro. Três décadas de evolução do funcionalismo público brasileiro (1986-2017)/Atlas do Estado Brasileiro - Felix Lopez e Erivelton Guedes/Diretoria de Estudos e Políticas sobre o Estado, Instituições e Democracia (Diest), 2019.

JORNAL CORREIO BRASILIENSE. EConomistas veem riscos de uma recessão profunda na atividade econômica. Disponível em: https://www.correiobraziliense.com.br/app/noticia/politica/2020/03/23/interna_politica,835982/ economistas-veem-riscos-de-uma-recessao-profunda-na-atividade-economic.shtml. Acesso em: 24 abr 2020.

SALVADOR, E. Fundo Público e o financiamento das Políticas Sociais no Brasil, trabalho apresentado no I simpósio orçamento público e políticas sociais, no dia 10 de abril de 2012, na Universidade Estadual de Londrina (UEL).

UOL. Pedidos de seguro-desemprego sobem 53\% em maio, a quase 1 miIhão de solicitações. Disponível em: https://economia.uol.com.br/noticias/ reuters/2020/06/09/pedidos-de-seguro-desemprego-sobem-53-em-maio-a-quase-1-milhao-de-solicitacoes.htm. Acesso em: 10 maio 2020.

\section{Notas}

1 Esse artigo contou com a colaboração dos alunos de Iniciação Científica Samara Reis e Emanuel Luca, do Curso de Serviço Social /UFBa, através dos levantamentos de dados e das discussões pertinentes ao projeto de pesquisa "Os funcionários públicos e a terceirização: um estudo do período pós-reforma do Estado no Brasil", apoiado pelo PIBIC/UFBa e pelo CNPq.

2 Professora titular do Programa de Pós-graduação em C. Sociais e do Programa de Pós-graduação em Serviço Social da UFBa. Pesquisadora do CRH - Centro de Es- 
tudos e Pesquisas em Humanidades, da UFBa e bolsista produtividade do CNPq. Brasil. Orcid: 0000-0003-0363-6883. E-mail: druckg@gmail.com

3 https://agenciadenoticias.ibge.gov.br/agencia-sala-de-imprensa/2013-agencia-de-noticias/releases/27534-pnad-continua-taxa-de-desocupacao-e-de-12-2-e-taxa-de-subutilizacao-e-de-24-4-no-trimestre-encerrado-em-marco-de-2020

4 Três décadas de evolução do funcionalismo público brasileiro (1986-2017)/Atlas do Estado Brasileiro - (IPEA) Felix Lopez e Erivelton Guedes. O Atlas é uma plataforma de dados e análises sobre o setor público desenvolvida pelo Ipea, sob a coordenação da Diretoria de Estudos e Políticas sobre o Estado, Instituições e Democracia (Diest).

5 No caso da Petrobras, a venda de ativos, fechamento de unidades (fertilizantes) com demissões em massa de trabalhadores próprios e terceirizados, levou a uma greve nacional de 20 dias em fevereiro de 2020. Segunda dados do DIEESE/FUP, em 2015, a Petrobras tinha 78.470 funcionários próprios e 158.076 terceirizados, em 2019, eram 57.983 próprios e 103.133 terceirizados, uma redução de $26 \%$ e $35 \%$ respectivamente, em apenas quatro anos.

6 Dados do Ministério da Economia. https://economia.uol.com.br/noticias/reuters/2020/06/09/pedidos-de-seguro-desemprego-sobem-53-em-maio-a-quase-1-milhao-de-solicitacoes.htm

7 Ver artigo "Condições de trabalho de entregadores via plataforma digital durante a Covid-19", Ludmila Costhek Abílio, Paula Freitas Almeida, Henrique Amorim, Ana Claudia Moreira Cardoso, Vanessa Patriota da Fonseca, Renan Bernardi Kalil, Sidnei Machado, Revista Jurídica Trabalho e Desenvolvimento Humano Procuradoria Regional do Trabalho da 15ª Região, junho 2020.

8 O período de elaboração desse texto, junho de 2020, não permitiu avaliar os resultados dessa paralisação nacional.

9 Dados disponíveis em: disponível em: https://www.tesourotransparente.gov. $\mathrm{br} / \mathrm{visualizacao/painel-de-monitoramentos-dos-gastos-com-covid-19,} \mathrm{em}$ 23/06/2020.

10 Em vídeo de reunião ministerial, divulgada amplamente por decisão do STF, O Ministro Paulo Guedes se referiu a essa decisão de congelamento salarial, como "a bomba no colo do inimigo" para se referir aos funcionários públicos.

11 "Em mais uma medida para combater os efeitos do coronavírus na economia, o Banco Central lançou um conjunto de medidas que aumentará a liquidez do Sistema Financeiro Nacional (SFN) em R\$ 1,2 trilhão. O objetivo é garantir que 
as instituições financeiras tenham recursos para atender às demandas do mercado. Além disso, as medidas de liberação de capital geram um potencial de expansão de $\mathrm{R} \$ 1,16$ trilhão no volume de crédito da economia. De acordo com a instituição fınanceira, isso dá segurança ao sistema para que as instituições financeiras mantenham e ampliem seus planos de concessões de crédito. https://bityli.com/pkQUT

12 Instituições financeiras como Goldman Sachs, afırma a recessão global e estima que a queda da economia na América Latina será de 1,2\%. O Itaú Unibanco estima uma queda de 2,2\% na América Latina e no Brasil, em 2020, pode chegar a mais de 1\%. A Tendências Consultoria, estima que pode haver um recuo de 1,4\%, e admite tombo maior, de 3,3\%, no pior dos cenários. O Centro de Macroeconomia Aplicada da Fundação Getulio Vargas de São Paulo (Cemap-FGV-SP) não descarta que o efeito da crise deverá se estender até 2023. Segundo o coordenador do estudo da FCV, Emerson Marçal, "Não é hora de pensar em gastar menos na área de Saúde, caso contrário, o prejuízo vai ser cada vez maior no PIB”. IN: Economistas veem riscos de uma recessão profunda na atividade econômica https:// www.correiobraziliense.com.br/app/noticia/politica/2020/03/23/interna_politica,835982/economistas-veem-riscos-de-uma-recessao-profunda-na-atividade-economic.shtml

13 O impacto econômico da pandemia do Covid-19 e a contração do PIB no primeiro trimestre de 2020: não é culpa da política de saúde pública, Pedro Paulo Zahluth Bastos, Luiz Celso Gomes-Jr, Lorena Salces Dourado, Gabriel Petrini, Paulo Robilloti e Antonio Ibarra, https://www.economia.unicamp.br/images/arquivos/nota_cecon_14_PIB_corona.pdf

14 https://www.imf.org/es/Publications/WEO/Issues/2020/06/24/WEOUpdateJune2020

15 Ver o acompanhamento dos gastos com a pandemia "Tesouro Transparente". https://www.tesourotransparente.gov.br 


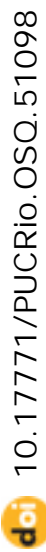

